See Article page 168.

\section{Commentary: Extrapleural pneumonectomy during myasthenic crisis: The urge to go big or go home}

\author{
Abbas E. Abbas, MD, MS, FACS
}

Myasthenia gravis (MG) is an uncommon autoimmune disease related to the thymus gland that may exist both separately and in conjunction with thymoma. MG affects $30 \%$ to $50 \%$ of patients with thymoma, ${ }^{1}$ and thymoma is found in $10 \%$ to $30 \%$ of patients with $\mathrm{MG}^{2}$ This crippling autoimmune disease usually runs a protracted progressive course. However, $10 \%$ to $20 \%$ of MG patients will develop myasthenic crises (MC), associated with respiratory failure and necessitating mechanical ventilation. ${ }^{3}$

Like MG, thymoma is also both rare and peculiar. Its biological behavior ranges from benign to extremely malignant, often invading local mediastinal structures, such as the innominate vein, phrenic nerve, pulmonary hilum, heart, aorta, and airways. Thymomas can also disseminate by "drop metastasis" to the pleural surfaces, much like ovarian cancer in the peritoneal cavity. Despite this, thymomas have a relatively slower progression and better prognosis than other similarly aggressive tumors. Surgical resection remains the mainstay of treatment and cure, although experienced thoracic surgeons will agree that the procedural difficulty can range from simple to challenging. This becomes important since it is well established that the most important factor affecting long-term prognosis apart from World Health Organization histological classification and

\footnotetext{
From the Division of Thoracic Surgery, Department of Thoracic Medicine and Surgery, Lewis Katz School of Medicine at Temple University, Philadelphia, Pa. Disclosure: The author reported no conflicts of interest.

The Journal policy requires editors and reviewers to disclose conflicts of interest and to decline handling or reviewing manuscripts for which they may have a conflict of interest. The editors and reviewers of this article have no conflicts of interest.

Received for publication March 22, 2020; revisions received March 22, 2020; accepted for publication March 27, 2020; available ahead of print April 6, 2020.

Address for reprints: Abbas E. Abbas, MD, MS, FACS, Department of Thoracic

Medicine and Surgery, Temple University Health System, Lewis Katz School of Medicine, 3401 N Broad St, Suite C-100, Philadelphia, PA 19035 (E-mail: abbas.abbas@temple.edu).

JTCVS Techniques 2020;2:173-4

2666-2507

Copyright (C) 2020 The Authors. Published by Elsevier Inc. on behalf of The American Association for Thoracic Surgery. This is an open access article under the CC BY-NCND license (http://creativecommons.org/licenses/by-nc-nd/4.0/).

https://doi.org/10.1016/j.xjtc.2020.03.033
}

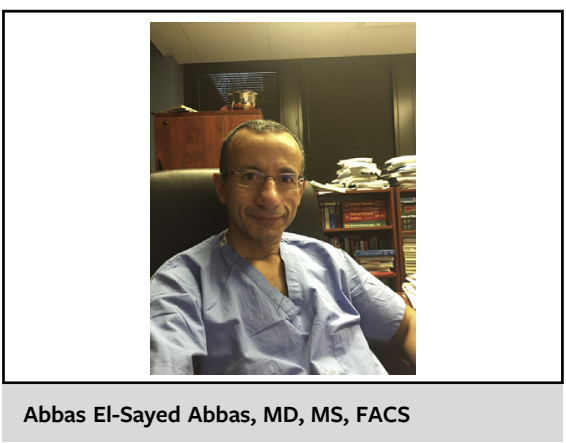

\author{
CENTRAL MESSAGE \\ Extended resections such as ex- \\ trapleural pneumonectomy for \\ thymoma are justified only in \\ operable patients with extensive \\ pleural dissemination and strong \\ expectation of complete eradi- \\ cation of the tumor.
}

Masaoka stage is completeness of resection. ${ }^{4-6}$ Therefore, surgeons must go to great lengths to achieve R0 resection. Luckily, these patients are often young and healthy and can generally tolerate heroically extensive resections when necessary.

Iqbal and colleagues ${ }^{7}$ reported a case of extended thymectomy with extrapleural pneumonectomy (ETEPP) for recurrent thymoma invading the myocardium in a young woman with history of previous $\mathrm{R} 1$ resection. This patient also had respiratory failure from MC, refractory to both plasmapheresis and intravenous immunoglobulin, but, amazingly, she recovered after surgery. Although this may be the first report of ETEPP in a patient in the throes of $\mathrm{MC}$, the operation has been described for pleurally disseminated thymoma (stage IVA) in several other studies. ${ }^{8-11}$ Two studies compared ETEPP with lesser resections such as pleurectomy and reported superior outcomes after ETEPP (Table 1). ${ }^{9,10}$

Of course, even in young patients, ETEPP is not without significant risk. The postoperative effect of pneumonectomy in a myasthenic patient who has not yet achieved remission and is unable to physically rehabilitate may be devastating. In addition, the danger of contaminating the pneumonectomy space or the peritoneal cavity by tumor droplets may be a major risk in this indolent tumor. ${ }^{8}$

Far fewer studies have suggested any form of surgery, let alone ETEPP during MC. ${ }^{12}$ In fact, thymectomy may 
TABLE 1. Studies of extrapleural pneumonectomy with and without pleurectomy for stage IVA thymoma

\begin{tabular}{|c|c|c|c|c|c|}
\hline Study & Procedure & 2-y survival, $\%$ & 5-y survival, \% & 10-y survival, $\%$ & DFS, $\%$ \\
\hline Wright, $2006^{8}$ & 5 ETEPP & NR & 75 & 50 & \\
\hline Huang et al, $2007^{9}$ & $\begin{array}{c}3 \text { ETEPP } \\
9 \text { Pleurectomy }\end{array}$ & NR & 100 & 100 & $\begin{array}{c}100 \\
66\end{array}$ \\
\hline Ishikawa et al, $2009^{10}$ & $\begin{array}{c}4 \text { ETEPP } \\
7 \text { Pleurectomy }\end{array}$ & NR & $\begin{array}{l}75 \\
16\end{array}$ & $\begin{array}{c}75 \\
0\end{array}$ & \\
\hline Yang et al, $2011^{11}$ & 7 ETEPP & 100 & NR & NR & \\
\hline
\end{tabular}

DFS, Disease-free survival; ETEPP, extended thymectomy with extrapleural pneumonectomy; $N R$, not reported.

cause postoperative $\mathrm{MC}$ in $12 \%-34 \%$ of patients. ${ }^{13-15}$ Therefore, most authorities recommend thymectomy for nonthymomatous MG only as an elective procedure when symptoms are under control and steroids are at a minimum. ${ }^{13,16}$

These various reports of thymoma and MG surgery raise several important and controversial questions:

- How far should one go in resecting thymomas?

- Does debulking alone play a role?

- What is the role of surgery during MC?

- What is the role of neoadjuvant or adjuvant therapy? Unfortunately, owing to the rarity of these tumors, the literature does not provide sufficient evidence to answer these questions. Most of the larger series span long time periods and include different histological classifications, therapies, and surgical techniques. This rarity also precludes the conduct of prospective trials. Multicenter organization registries, such as the International Thymic Malignancy Interest Group, are important to improving our understanding of this disease.

Many of the "rules" that we follow in treating advanced thymoma are based on our collective wisdom and experience. Perhaps the most crucial of these rules is the importance of achieving complete resection of the tumor whenever possible. Heroic resections are justified only after a careful evaluation of the specific tumor and patient characteristics. Such operations should be performed only in operable patients with extensive pleural dissemination and strong expectation of complete eradication of the tumor. Operating during $\mathrm{MC}$ on a ventilated patient may be associated with poor outcomes and cannot be considered routinely safe, especially when the planned resection is a reoperative ETEPP with myocardial resection. In such cases, it is sometimes better to not go big that day but to go home instead and wait to fight another day.

\section{References}

1. Regnard JF, Magdeleinat P, Dromer C, Dulmet E, de Montpreville V, Levi JF, et al. Prognostic factors and long-term results after thymoma resection: a series of 307 patients. J Thorac Cardiovasc Surg. 1996;112:376-84.

2. Thomas CR, Wright CD, Loehrer PJ. Thymoma: state of the art. J Clin Oncol. 1999; 17:2280-9.

3. Berrouschot J, Baumann I, Kalischewski P, Sterker M, Schneider D. Therapy of myasthenic crisis. Crit Care Med. 1997;25:1228-35.

4. Masaoka A, Monden Y, Nakahara K, Tanioka T. Follow-up study of thymomas with special reference to their clinical stages. Cancer. 1981;48:2485-92.

5. Blumberg D, Port JL, Weksler B, Delgado R, Rosai J, Bains MS, et al. Thymoma: a multivariate analysis of factors predicting survival. Ann Thorac Surg. 1995;60: 908-13; discussion 914

6. Nakagawa K, Asamura H, Matsuno Y, Suzuki K, Kondo H, Maeshima A, et al. Thymoma: a clinicopathologic study based on the new World Health Organization classification. J Thorac Cardiovasc Surg. 2003;126:1134-40.

7. Iqbal F, Shokrzadeh C, Nawgiri R, Okereke I. Extrapleural pneumonectomy with en bloc myocardial resection for advanced thymoma. J Thorac Cardiovasc Surg Tech. 2020;2:168-70.

8. Wright CD. Pleuropneumonectomy for the treatment of Masaoka stage IVA thymoma. Ann Thorac Surg. 2006;82:1234-9.

9. Huang J, Rizk NP, Travis WD, Seshan VE, Bains MS, Dycoco J, et al. Feasibility of multimodality therapy including extended resections in stage IVA thymoma. $J$ Thorac Cardiovasc Surg. 2007;134:1477-83; discussion 1483-4.

10. Ishikawa Y, Matsuguma H, Nakahara R, Suzuki H, Ui A, Kondo T, et al. Multimodality therapy for patients with invasive thymoma disseminated into the pleural cavity: the potential role of extrapleural pneumonectomy. Ann Thorac Surg. 2009;88:952-7.

11. Yang HC, Yoon YS, Kim HK, Choi YS, Kim K, Shim YM, et al. En bloc extended total thymectomy and extrapleural pneumonectomy in Masaoka stage IVA thymomas. J Cardiothorac Surg. 2011;6:28.

12. Onuki T, Ueda S, Otsu S, Yanagihara T, Kawakami N, Yamaoka M, et al. Thymectomy during myasthenic crisis under artificial respiration. Ann Thorac Cardiovasc Surg. 2019;25:215-8.

13. Ando T, Omasa M, Kondo T, Yamada T, Sato M, Menju T, et al. Predictive factors of myasthenic crisis after extended thymectomy for patients with myasthenia gravis. Eur J Cardiothorac Surg. 2015;48:705-9; discussion 709.

14. Leuzzi G, Meacci E, Cusumano G, Cesario A, Chiappetta M, Dall'armi V, et al. Thymectomy in myasthenia gravis: proposal for a predictive score of postoperative myasthenic crisis. Eur J Cardiothorac Surg. 2014;45:e76-88; discussion e88.

15. Watanabe A, Watanabe T, Obama T, Mawatari T, Ohsawa H, Ichimiya Y, et al. Prognostic factors for myasthenic crisis after transsternal thymectomy in patients with myasthenia gravis. J Thorac Cardiovasc Surg. 2004;127:868-76.

16. Sanders DB, Wolfe GI, Benatar M, Evoli A, Gilhus NE, Illa I, et al. International consensus guidance for management of myasthenia gravis: executive summary. Neurology. 2016;87:419-25. 